\title{
WIDEBAND HF SIGNALS DISPERSION DISTORTION COMPENSATOR BASED ON DIGITAL FILTER BANKS. THEORY AND APPROBATION
}

Denis S. Chirov,

Moscow Technical University of Communications

and Informatics, Moscow, Russia,

den-chirov@yandex.ru

Elizaveta 0 . Lobova,

Moscow Technical University of Communications

and Informatics, Moscow, Russia,

lizabeth2@mail.ru
Keywords: HF communication, wideband signals, dispersion distortion, digital filter banks, ionosphere

\begin{abstract}
The article proposes a computationally effective scheme of the dispersion distortions compensation device, based on the modification of the classical 2M-channel digital filter banks. The main idea of dispersion compensation is equalization of the delay and elimination of the phase shift, because the frequency dispersion of the signal is the delay of the signal at each frequency and the phase shift. The dispersion distortions compensation device involves the set of FIR filters and the delay line. The set of FIR filters eliminate fractional delay are implemented in the compensation scheme by means of the signal re-digitization with the help of the 19-th degree interpolation polynomial. Each of the FIR filters is multiplied by a coefficient that eliminates the certain phase shift. The delay line eliminates the integer part of the delay. Also, this article estimates the required number of channels in a dispersion compensation device based on a bank of digital filters and compares compensation algorithms on the basis of a filter bank and a filter-compensator. Analytical expressions are obtained for the approximate calculation of the maximum and standard deviations of the phase response of the system, reflecting the dependence of the phase response on the number of frequency subchannels, the order of the interpolation polynomial of the interpolator, the length of the polyphase components of the prototype filter, the slope of the dispersion characteristic, and the passband of the filter bank. Besides, a theoretical and experimental study is concluded, the purpose of which is to confirm the performance and efficiency (availability in terms of the signal-to-noise ratio) of the algorithms for compensating for dispersion distortion of broadband signals in the decameter band, embedded in a digital analysissynthesis filter bank.
\end{abstract}

Information about authors:

Denis S. Chirov, Doct. Tech. Sciences, docent, chief researcher at SRD MTUCI, Moscow, Russia

Elizaveta O. Lobova, postgraduate student MTUCl, minor researcher at SRD MTUCI, Moscow, Russia

Для цитирования:

Чиров Д.С., Лобова Е.О. Компенсатор дисперсионных искажений широкополосных сигналов декаметрового диапазона, построенный на базе банка цифровых фильтров. Теория и эксперимент // Т-Сотm: Телекоммуникации и транспорт. 2020. Том I4. №4. С. 57-65.

For citation:

Chirov D.S., Lobova E.O. (2020) Wideband HF signals dispersion distortion compensator based on digital filter banks. Theory and approbation. T-Comm, vol. 14, no.4, Pp. 57-65. (in Russian) 


\section{Introduction}

At present, decameter radio communication is actively used for communication in remote and inaccessible regions of the world. Also, decameter communication is an actual type of radio communication for regions that have suffered serious damage due to natural disasters.

Modern development of HF communication systems is aimed at increasing the information transmission rate by increasing the frequency band used [1-4]. When receiving signals with an extended spectrum, it becomes necessary to take into account the influence of the frequency dispersion of the ionospheric channel, since it leads to significant distortions of the signal and a decrease in the quality of information reception in general [5-7]. An actual problem is to assess the parameters of the frequency dispersion of the ionospheric channel and develop algorithms and devices for compensating for dispersion distortion of wideband signals [8-10, 13-15].

Also, in broadband data transmission systems, digital filter banks have been actively used for signal processing for a long time $[11,12]$.

Filter banks are used to solve such problems as: estimating the power spectral density in radio monitoring tasks and cognitive radio systems, adaptive rejection of narrow-band interference, efficient message coding, etc. Therefore, for the decameter range, it is relevant to use a filter bank and a dispersion distortion compensation device together. This problem is usually solved by using a special compensator filter (a filter consistent with the characteristics of the channel). However, in order to minimize the overall computational complexity of the algorithms for processing the received signals, it is urgent to introduce an algorithm for compensating dispersion distortions directly into the synthesis system of a bank of digital filters which are somehow used on the receiving side. Therefore, the compensation of dispersion distortions introduced into the bank of digital filters in order to eliminate the aforementioned losses is an urgent task.

\section{Filter Bank for Dispersion Distortion Compensation}

As a channel model with a dispersion frequency, a channel model with a linear dependence of the group delay of the signal on the central frequency (linear dispersion characteristic with slope s [3]) is adopted. The transfer function of the ionospheric channel in the absence of multipath signal propagation can be written in the form

$$
\dot{U}(j 2 \pi f)=\mathrm{e}^{-j \pi s f^{2}}, f \in\left[-f_{\partial} / 2 ; f_{\partial} / 2\right]
$$

where $f_{\partial}$ - is the sampling frequency, $s-$ is the slope of the dispersion characteristic (inclination).

The phase response of the ionospheric channel is described by a quadratic frequency dependence, and the group propagation delay is described by a linear frequency dependence with the slope $s \mu \mathrm{s} / \mathrm{MHz}$.

Consider a system of banks of digital filters of analysissynthesis with an ideal recovery. The bank consists of $2 M=64$ modulated complex exponent of analysis filters and the same number of synthesis filters $[11,12,16]$. Let us assume that $\left.H_{k}(z)\right|_{z=e^{j 2 \pi f T}}=H_{k}\left(e^{j 2 \pi f T}\right)$ and $\left.F_{k}(z)\right|_{z=e^{j 2 \pi f T}}=F_{k}\left(e^{j 2 \pi f T}\right)$ are respectively the frequency characteristics of the analysis filters and the synthesis filters, respectively, $T=1 / f_{s}$.
We can show that the signal distorted by the ionospheric channel at the output of the $k$-th analysis filter can be represented as

$$
\tilde{x}_{k}(n) \simeq x_{k}\left(n-n_{k}\right) e^{j \pi f_{k}^{2} s}
$$

where $x_{k}(n)$ - the signal undistorted by the frequency dispersion at the output of the analysis filter, $n_{k}=\operatorname{round}\left(\frac{f_{k} s}{T}\right)+$ const - the signal delay in the $k$-th channel of the analysis system, expressed in the sampling intervals $T$, round $(x)$ is the rounding function to the nearest whole.

The frequency dispersion of the signal is the signal delay at each frequency and the phase shift (see (2)), and for each frequency the delay and phase shift assume different values. Therefore, in order to eliminate the dispersion distortions, it is necessary to "equalize" the delay, which leads to the introduction into the bank's system of analysis and synthesis of an additional delay line before the synthesis filters and the $e^{-j \pi f_{k}^{2} s}$ phase shift of the signals . Such a solution does not change the algorithm for calculating the synthesis bank filters in any way and does not depend on their specific type.

Figure 1 shows a computationally efficient compensation scheme for frequency dispersion of filter banks. To reduce the number of computational operations, the algorithm described in $[12,16]$ was applied. The main idea of such an algorithm is to represent synthesis filters (and analysis) in the form of a set of polyphase components of the original prototype filter $E_{k}(z)$, applying the FFT algorithm, and processing the signal at a low sampling frequency (i.e., before increasing $M$ times).

In this case, it becomes necessary to introduce interpolation filters that compensate fractional delays.

In the proposed scheme, the compensation of group delay is carried out at a low sampling frequency. Moreover, one cannot limit oneself to introducing only compensation delay lines, since the delay compensation error will be times greater (since the sampling interval is times larger).

Therefore, a system of FIR filters $K_{k}(z), k=0 . .2 M-1$, eliminating fractional delay is implemented in the compensation circuit by means of the signal re-digitization with the help of the 19-th degree interpolation polynomial, and the delay line $z^{-\tilde{\tilde{n}}_{k}}$ eliminating the integer part of the delay, $\tilde{\tilde{n}}_{k}=\operatorname{round}\left(f_{k} s M F_{\partial}\right)$, $\operatorname{round}(x)$ - is a function that separates the integer part of the fractional number. Preliminary $M_{0}$ times interpolation is performed in order to reduce the signal distortion caused by the nonuniformity of the amplitude response and the nonlinearity of the phase response of the interpolating FIR filter. This allows, by processing one copy of the signal in the frequency domain, to reduce the amplitude-phase distortions that contribute to the interpolation FIR filter with group delay compensation. The value $M_{0}$ is chosen small: 1 (without pre-interpolation), 2 or 4 . The length of the interpolation FIR filter is equal to $N_{\text {inter }}=N_{\text {poly }} M_{0}-1$. 
The impulse response of the interpolation FIR filter is calculated as 19-degree Lagrange polynomial values at the corresponding time instants, provided that the input action, on the basis of which the polynomial coefficients are calculated, was unit-impulse. Moments of time correspond to the fractional delay value, which must be compensated.

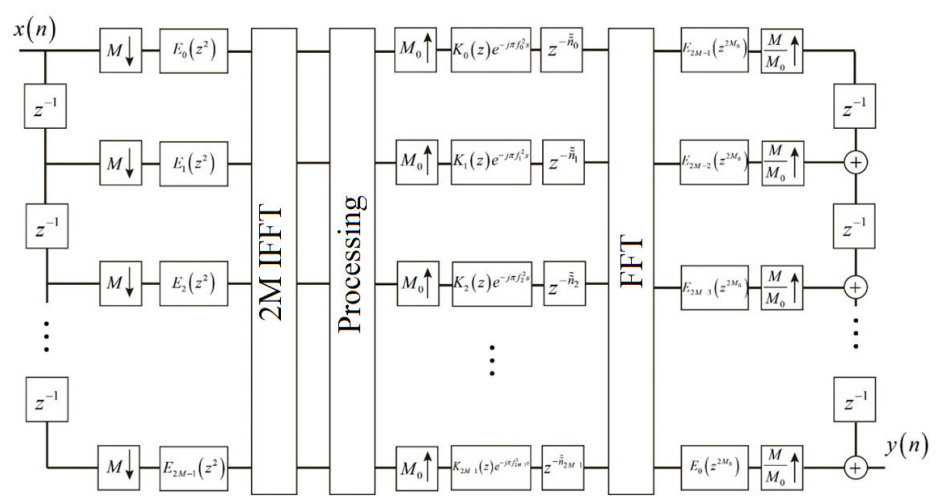

Figure 1. Computationally efficient filter bank with dispersion compensation

The transfer function of the channel-bank of the above filter bank is

$T(z)=\sum_{k=0}^{2 M-1} \sum_{l=0}^{M-1} U\left(e^{-j \frac{2 \pi}{M} l} z\right) H_{k}\left(z e^{-j \frac{2 \pi}{M} l}\right) K_{k}\left(z^{\frac{M}{M_{0}}}\right) e^{-j \pi f_{k}^{2} s} z^{-\tilde{n}_{k}} F_{k}(z)$

where

$$
H_{k}(z)=\sum_{q=0}^{2 M-1} z^{-q} E_{q}\left(z^{2}\right) e^{j \frac{2 \pi}{2 M} k q}
$$

$F_{k}(z)=\sum_{u=0}^{2 M-1} z^{-(2 M-1-u)} E_{2 M-1-u}\left(z^{2 M}\right) e^{-j \frac{2 \pi}{2 M} k u}-\mathrm{c} \quad$ putationally

efficient representation of the transfer functions of analysis filters and synthesis filters, $E_{q}\left(z^{2 M}\right)$ и $E_{2 M-1-u}\left(z^{2 M}\right)$ - polyphase components of analysis and synthesis filters.

The summation over $q$ calculates the $k$-th coefficient of the inverse discrete Fourier transform (DFT) with the block length $2 M$ (excluding the normalizing factor), where $k$ is the filter index, and summing over $u$ calculates the $k$-th direct DFT coefficient with the block length $2 M$.

The figures Figure $\mathbf{3}$ and 4show graphs:

1. Frequency response of the channel + bank with compensation system $\left.T(z)\right|_{z=e^{j 2 \pi f T}}$.

2. Frequency response of the aliasing components of the filter bank transfer function taking into account the channel and distortion compensation $\left.T_{\text {aliasing }}(z)\right|_{z=e^{j 2 \pi f T}}$.

The calculations were carried out for the bank of 64 filters $(2 M=64)$ with the length of the filter $N=1024$, satisfying the ideal reconstruction condition, in which aliasing components are mutually destroyed at the synthesis stage. It can be seen from the indicated dependencies that the superimposed components of the filter bank with compensation for dispersion distortions are not fully compensated, and as a result there is no complete signal recovery at the output of the filter bank.

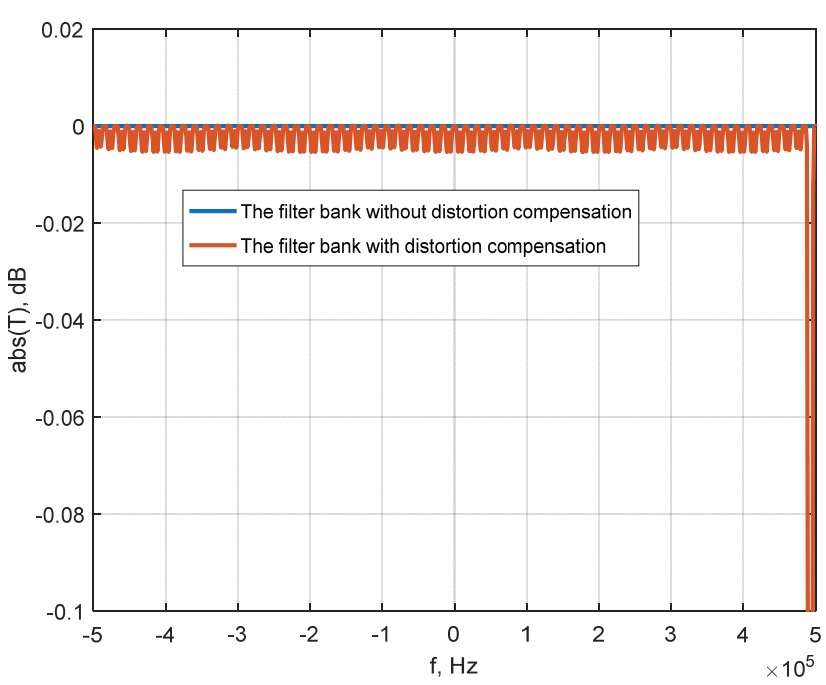

Figure 2. Frequency response of the channel + bank with compensation system

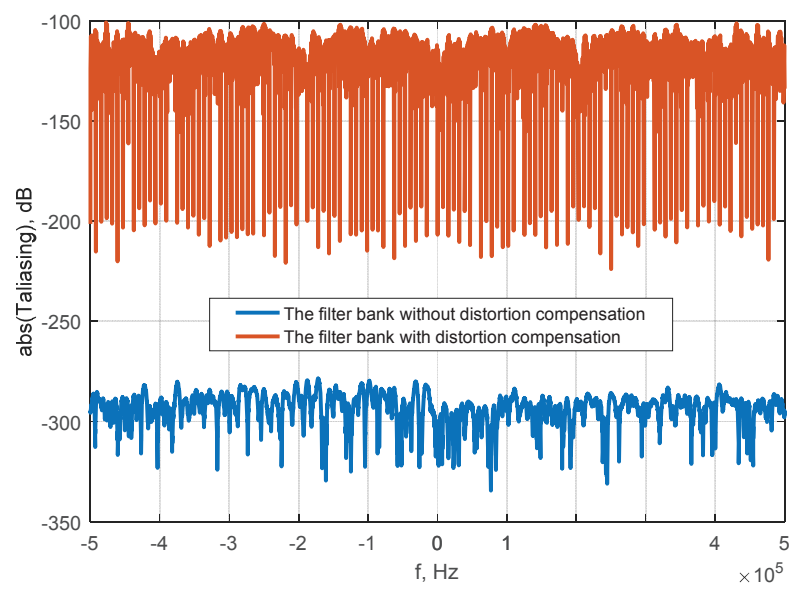

Figure 3. Frequency response of the aliasing components of the filter bank transfer function taking into account the channel and distortion compensation

\section{The estimation of the minimum number of filters in the filter bank to ensure a given level of phase distortion}

We can show [17] that the phase response of the useful component of the filter bank without taking into account the channel and without the compensation system is strictly linear and corresponds to the signal delay during processing:

$$
\varphi_{T}\left(e^{j \hat{\omega}}\right)=\hat{\omega}\left(1-N_{f i t}\right) \text {. }
$$

Then, with compensation, the following condition must be met

$$
\varphi_{T_{0}}\left(e^{j \hat{\omega}}\right) \rightarrow \varphi_{T}\left(e^{j \hat{\omega}}\right)+\text { const } .
$$

In other words, the compensation should eliminate the channel effect, which is reflected in the appearance of the quadratic part in the phase response. For comparison, it is convenient to use the phase response of the channel + filter bank system after eliminating the linear part. In view of the above, (4) can be rewritten as

$$
\tilde{\varphi}_{T_{0}}\left(e^{j \hat{\omega}}\right)=\varphi_{T_{0}}\left(e^{j \hat{\omega}}\right)-\hat{\omega}\left(1-N_{f i t}\right) \rightarrow \text { const },
$$


where $\tilde{\varphi}_{T_{0}}\left(e^{j \hat{\omega}}\right)$ - the channel phase response + bank filter system after eliminating the linear part.

Figure 4 shows a graph of the phase response of the channel + system of the useful component of the filter bank transfer function with compensation at $s=80 \mu \mathrm{s} / \mathrm{MHz}$ for a different number of filters after eliminating the linear part corresponding to the signal delay in the filter bank. The figure shows that the more filters are used, the better the quality of compensation (The channel phase response closer to zero, see the formula (5)). The filter near the frequency $\hat{\omega}= \pm \pi$ is not taken into account $(k \neq M)$, because leads to a failure in the frequency response at the boundary with one of the neighboring filters, i.e. introduces distortions in the final frequency response of the compensator.

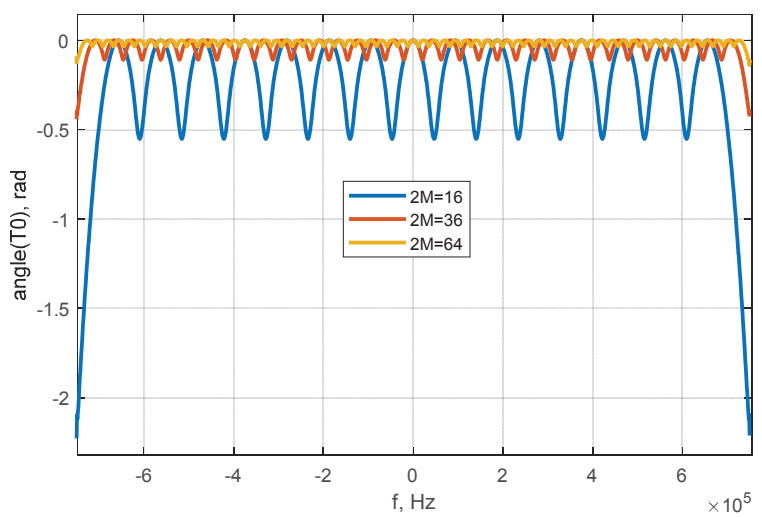

Figure 4. The phase response of the channel system + the useful component of the transfer function of the filter bank after eliminating the linear part for $s=80 \mu \mathrm{s} / \mathrm{MHz}$

The necessary number of filters to ensure a given level of phase response deviation can be obtained from the solution of the optimization problem using the root mean square criterion (RMS) or minimax criterion. For both criteria, when solving the optimization problem, the variable parameter is the number of filters $2 M$.

For a filter bank, the RMS criterion of optimality has the form

$$
\begin{aligned}
& \varphi_{r m s}=\sqrt{\int_{F}(\varphi(2 \pi f)-\langle\varphi(2 \pi f)\rangle)^{2} d f} \rightarrow \min _{2 M}, \\
& \langle\varphi(2 \pi f)\rangle=\int_{F} \varphi(2 \pi f) d f=\text { const }
\end{aligned}
$$

where $\varphi_{r m s}$ - permissible deviation of the phase response from zero, $F$ - frequency range (approximation interval).

The level of quality for minimax criterion is defined as the maximum deviation from the average between the maximum and minimum deviations from zero in the passband, because this average shows general phase shift of the signal and does not distort it. The minimax criterion for a filter bank can be written as

$$
\varphi_{\min \max }=\frac{\max _{f \in F}(\varphi(2 \pi f))-\min _{f \in F}(\varphi(2 \pi f))}{2} \rightarrow \min _{2 M},
$$

where $\varphi_{\min \max }-\mathrm{p}$ missible deviation of the phase response from average.
It is obvious that the phase deviation from zero is due to residual dispersion distortions of the signal within the passband of individual filters in the filter bank. The more filters there are, the narrower their passband, the less the amount of residual distortion.

We introduce the function

$$
F\left(M, s, F_{s}\right)=\frac{\Delta f}{\Delta f_{c o h}}=\frac{F_{s}}{2 M} \sqrt{\frac{\pi|s|}{4}}=p_{f},
$$

where $\Delta f=F_{s} / 2 M-$ bandwidth of one filter from the filter bank, $p_{f}$ - dispersion coefficient of the channel formed by a separate filter from the filter bank, $\Delta f_{c o h}=\sqrt{4 /(\pi|s|)}-$ channel coherence band with frequency dispersion.

Find $F\left(M, s, F_{s}\right)$ in such a way that

$$
F\left(M, s, F_{s}\right) \cong \text { const }, \varphi_{\min \max }=\text { const }
$$

for the considered values of $M, s, F_{s}$ and $\varphi_{\min \max }$.

Then from relation (3), $2 M$ can be expressed for a known slope of the dispersion characteristic $s$, sampling frequency $F_{s}$, and a given level $\varphi_{\min \max }$.

From Figure 4 we can conclude that the phase deviation increases from the central frequency of the passband of a single filter and grows to its boundary. Given the channel model

$$
\varphi_{\min \max } \sim \pi s\left(\frac{\Delta f}{2}\right)^{2} .
$$

We seek (3) taken into account as

$$
\begin{aligned}
& \sqrt{\varphi_{\min \max }}=C_{1} F\left(M, s, F_{s}\right)=C_{1} \frac{\Delta f}{\Delta f_{c o h}}, \\
& C_{1} \text { - constant. }
\end{aligned}
$$

As a result of numerical calculations for $M_{0}=2, N_{\text {poly }}=16$ the sets of individual values $\varphi_{\min \max }$ and $F\left(M, s, F_{s}\right)$ the desired constant $C_{1}$ was found by the least squares method and the expression was found

$$
\begin{aligned}
& \varphi_{\text {min } \max }=0.7073^{2} F^{2}\left(M, s, F_{s}\right)=\left(\frac{0.7073 F_{s}}{2 M}\right)^{2} \frac{\pi|s|}{4} ; \\
& C_{1}=0.7073 .
\end{aligned}
$$

Similarly, an expression was obtained for the standard deviation of the phase $\varphi_{r m s}$

$$
\begin{aligned}
& \varphi_{r m s}=0.575^{2} F^{2}\left(M, s, F_{s}\right)=\left(\frac{0.575 F_{s}}{2 M}\right)^{2} \frac{\pi|s|}{4}, \\
& C_{1}=0.575
\end{aligned}
$$

Figure 5 shows a comparison of the theoretical (calculated by formulas $(7,8)$ and experimental dependences of $\varphi_{r m s}$ and $\varphi_{\min \max }$ on the number of filters $2 M$ for four different values of the slope $s$ and for the sampling frequency $F_{s}=1.5 \mathrm{MHz}$.

Figure 5 shows that the larger the filter bank (the larger the parameter $2 M$ ), the smaller the values of $\varphi_{r m s}$ and $\varphi_{\min \max }$ can 
be obtained for different slopes of the dispersion characteristic. Also, note that the larger $s$, the more difficult the compensation, and accordingly, a larger filter bank is required to achieve the required values of $\varphi_{r m s}$ and $\varphi_{\min \max }$.
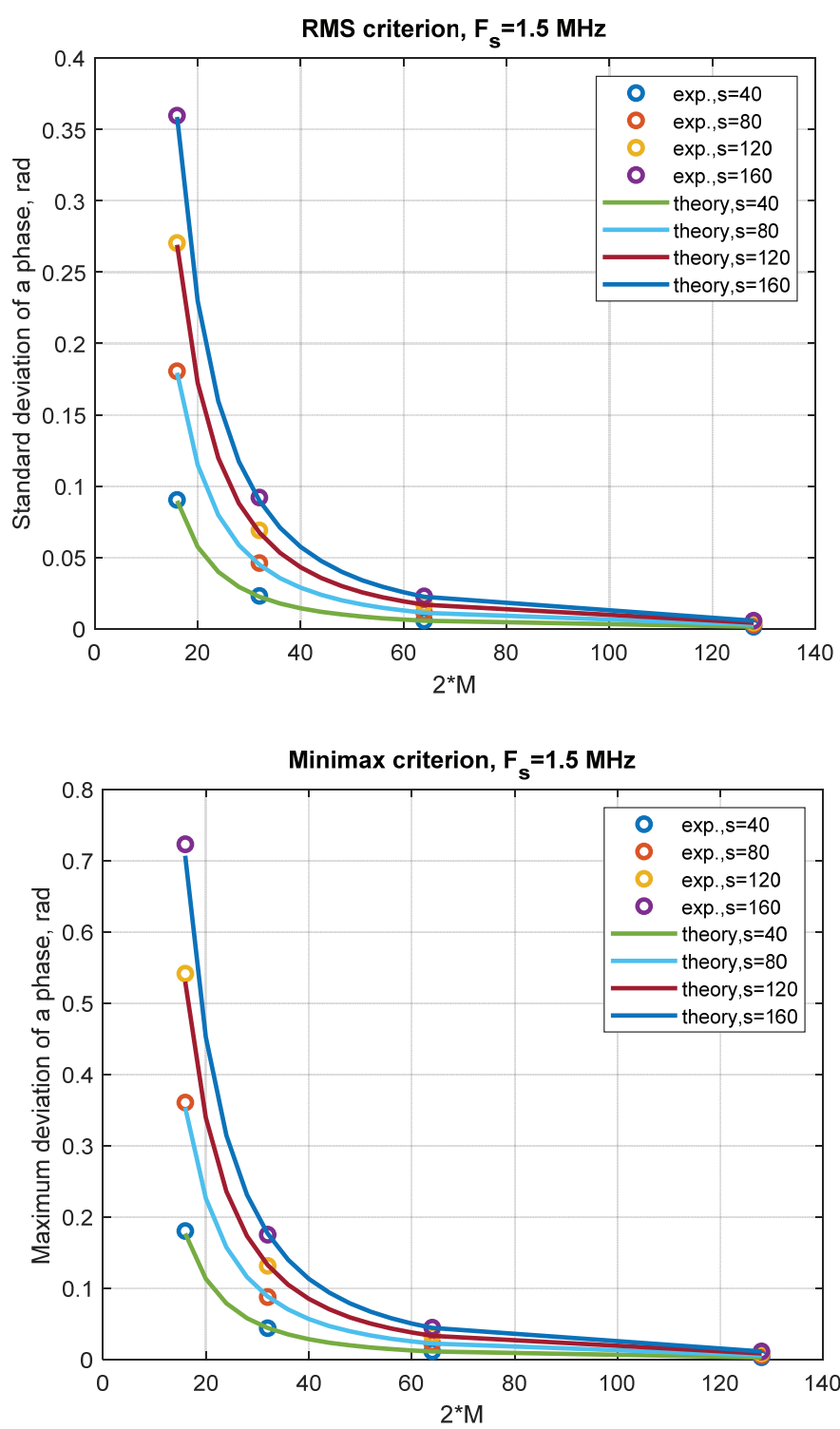

Figure 5. Theoretical and experimental dependences of the phase deviation on the number of filters in the filter bank, the RMS criterion and minimax criterion

Figure 6 shows the dependence of the number of arithmetic operations on the length of the interpolation polynomial of the interpolator filter $N_{p o l y}$ for different values of $M_{0}$ and for $m=8,2 M=64$. The figure shows that the number of arithmetic operations increases linearly with increasing $N_{\text {poly }}$. Also, with a 2-fold increase in $M_{0}$, the number of computational operations also increases by about 2 -fold.

Figure 7 shows the dependence of the maximum phase deviation on $N_{\text {poly }}$ for various values of $M_{0}$ and for $m=8$, $2 M=64$. The figure shows that the dependence of the maxi- mum phase deviation on $N_{\text {poly }}$ for various values of $M_{0}$ is small (maximum difference between maximum phase deviation for $M_{0}=1$ and $M_{0}=4$ is $0.3 \cdot 10^{-3}$ for $N_{p o l y}=10$ ). Therefore, it is possible to set $M_{0}=1$ in the compensator in order to significantly reduce computational costs.

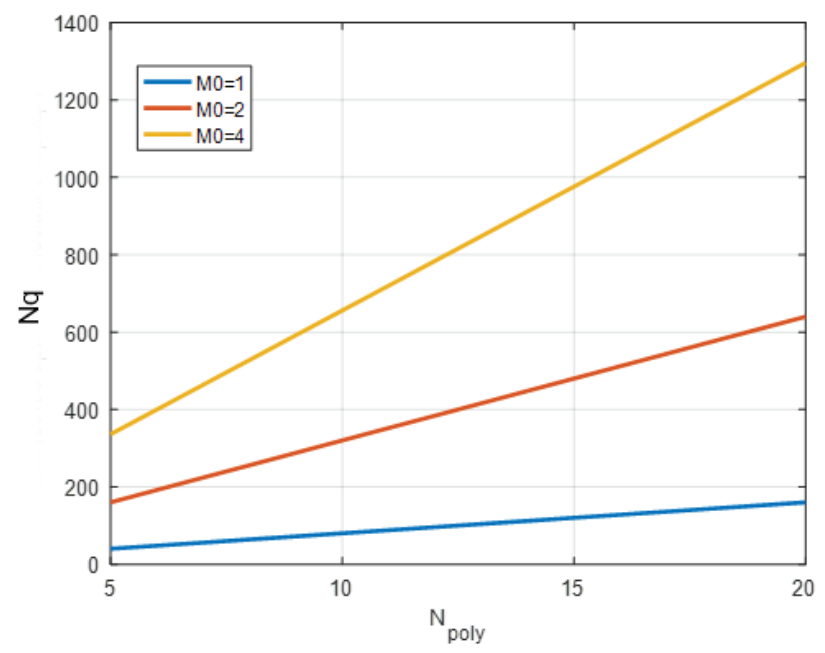

Figure 6. The dependence of the number of arithmetic operations on the length of the interpolation polynomial of the interpolator filter $N_{\text {poly }}$

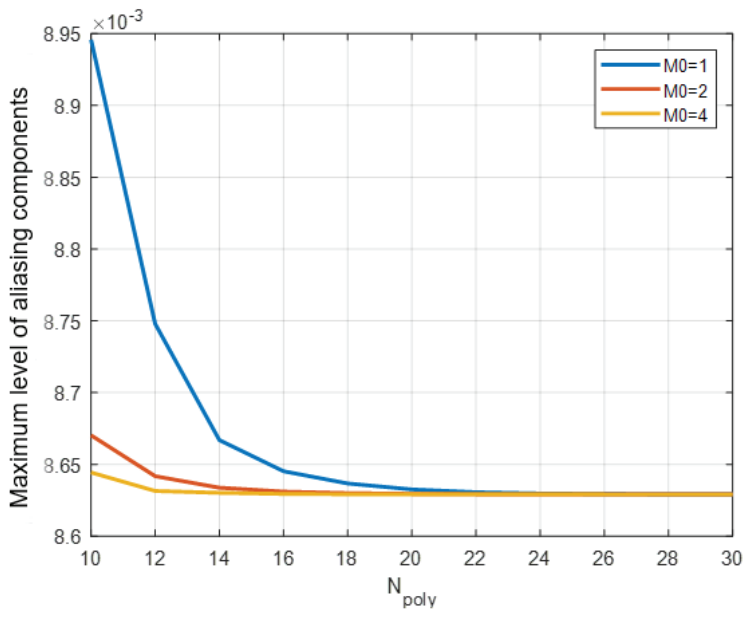

Figure 7. The dependence of the maximum phase deviation on $N_{\text {poly }}$ for various values of $M_{0}$

\section{The comparison of the computational efficiency of compensation algorithms in the filter bank}

This section presents the results of comparing the computational efficiency of the proposed compensation device and filtercompensator. The filter-compensator is a matched filter (MF), consistent with the characteristics of the channel.

Tables Table 1 and 2 show a comparison of the number of real multiplication-addition operations in the compensator necessary to achieve the set values $\varphi_{r m s}$ and $\varphi_{\min \max }$ for different slopes $s, \mu \mathrm{s} / \mathrm{MHz}$ for $F_{s}=1 \mathrm{MГц,} M_{0}=1$. Since the filter 
bank implemented according to the computational scheme has the number of channels determined through $2^{n}$, where $n=2,3, \ldots$, then the levels $\varphi_{r m s}$ and $\varphi_{\min \max }$ can vary greatly change depending on $2 M$. Therefore, when comparing fixed levels $\varphi_{r m s}$ and $\varphi_{\text {min max }}$, if the deviation in the filter bank reaches a lower value than the fixed one, this is indicated in brackets.

Table 1

The comparison of the number of material operations of multiplication and addition, which the filter compensator performs and the filter bank when compensating to achieve the specified values $\varphi_{r m s}$

\begin{tabular}{|c|c|c|c|}
\hline $\begin{array}{c}S, \\
\mu \mathrm{sHz}\end{array}$ & $\varphi_{r m s}$, rad & $\begin{array}{c}\text { The number of channels in } \\
\text { the filter bank, the length of } \\
\text { the interpolation polynomi- } \\
\text { al, and the number of real } \\
\text { computational operations of } \\
\text { the compensator } \\
2 M, N_{p o l y}, N_{q}\end{array}$ & $\begin{array}{c}\text { The number of real } \\
\text { computational } \\
\text { operations of the } \\
\text { filter-compensator }\end{array}$ \\
\hline 40 & 0.004 & $64,10,80$ & 119 \\
\hline 80 & 0.008 & $64,10,80$ & 119 \\
\hline 120 & 0.013 & $64,10,80$ & 119 \\
\hline 160 & $\begin{array}{c}0 . \\
\text { for filter } \\
\text { bank - } \\
0.015)\end{array}$ & $64,10,80$ & 118 \\
\hline
\end{tabular}

Table 2

The comparison of the number of material operations of multiplication and addition, which the filter compensator performs and the filter bank when compensating to achieve the specified values $\varphi_{\text {min max }}$

\begin{tabular}{|c|c|c|c|}
\hline $\begin{array}{c}s \\
\mu \mathrm{s} / \mathrm{MHz}\end{array}$ & $\varphi_{\min \max }$ & $\begin{array}{l}\text { The number of channels in } \\
\text { the filter bank, the length of } \\
\text { the interpolation polynomi- } \\
\text { al, and the number of real } \\
\text { computational operations of } \\
\text { the compensator } \\
2 M, N_{\text {poly }}, N_{q}\end{array}$ & $\begin{array}{l}\text { The number of real } \\
\text { computational } \\
\text { operations of the } \\
\text { filter-compensator }\end{array}$ \\
\hline 40 & 0.015 & $32,10,80$ & 166 \\
\hline 80 & $\begin{array}{c}0.01 \text { (for } \\
\text { filter bank } \\
-0.0076)\end{array}$ & $64,12,96$ & 182 \\
\hline 120 & $\begin{array}{c}0 \\
\text { (for filter } \\
\text { bank - } \\
0.012 \text { ) }\end{array}$ & $64,12,96$ & 182 \\
\hline 160 & 0.015 & $64,12,96$ & 199 \\
\hline
\end{tabular}

From tables 1, 2 we can draw the following conclusions:

1. The compensator in the filter bank with the same number of channels and computational operations provides approximately the same values of $\varphi_{r m s}$ and $\varphi_{\min \max }$, while the compensator filter, due to the large non-uniformity of the phase response, the values of $\varphi_{r m s}$ and $\varphi_{\min \max }$ can differ by an order of magnitude with the same number of computational operations;
2. The compensator in the filter bank for the given values of $\varphi_{r m s}$ requires computational operations less than 1.5 times than the filter-compensator, and for the given values of $\varphi_{\min \max }$, it is less than about 2 times.

\section{The comparison of theoretical and experimental compensation results}

The signal-to-noise ratio (SNR) at the MF output at the time the signal ends for a computationally efficient filter bank circuit with frequency dispersion compensation is defined as

$$
\left(\frac{P_{c}}{P_{u}}\right)_{\text {э kомn }}=\frac{\frac{1}{N_{D F T}}\left|\sum_{i=-\frac{N_{D F T}}{2}}^{\frac{N_{D F T}}{2}-1} \dot{Q}_{i} e^{\frac{j 2 \pi}{N_{D F T}} i n_{*}}\right|^{2}}{2 \sigma^{2}{ }_{u}\left(\left.\sum_{i=-\frac{N_{D F T}}{2}}^{\frac{N_{D F T}}{2}-1}\left|\dot{J}_{i}\right|^{2}\right|^{2}\right.},
$$

where

$$
\begin{gathered}
\dot{J}_{i}=\dot{K}_{c \phi i} e^{\frac{j 2 \pi}{N_{D F T}} i n_{*}} \sum_{k=0}^{2 M-1} \dot{H}_{k i} \dot{F}_{k i} \dot{\dot{K}}_{k i} e^{-j \pi\left(\frac{f_{k}}{N_{D F T}}\right)^{2} s} e^{\frac{-j 2 \pi}{N_{D F T}} i \tilde{n}_{k}}+ \\
+\sum_{l=1}^{M-1} \dot{K}_{c \phi(i+b l)} e^{\frac{j 2 \pi}{N_{D F T}}(i+b l) n_{k}} \sum_{k=0}^{2 M-1} \dot{H}_{k i} \dot{F}_{k(i+b l)} e^{-j \pi\left(\frac{f_{k}}{N_{D F T}}(i+b l)\right)^{2} s} e^{\frac{-j 2 \pi}{N_{D F T}}(i+b l) i \tilde{\tilde{n}}_{k}} \\
\dot{Q}_{s d i}=\dot{S}_{i} \dot{U}_{i} \dot{K}_{c \phi i} \sum_{k=0}^{2 M-1} \dot{H}_{k i} \dot{F}_{k i} \hat{\dot{K}}_{k i} e^{-j \pi\left(\frac{f_{k}}{N_{D F T}}\right)^{2} s} e^{\frac{-j 2 \pi}{N_{D F T}} \tilde{\tilde{n}}_{k}}+ \\
+\dot{K}_{c \phi i} \sum_{l=1}^{M-1} \dot{S}_{i-b l} \dot{U}_{i-b l} \sum_{k=0}^{2 M-1} \dot{H}_{k(i-b l)} \dot{F}_{k i} \hat{\dot{K}}_{k i} e^{-j \pi\left(\frac{f_{k}}{N_{D F T}} i\right)^{2} s} e^{\frac{-j 2 \pi}{N_{D F T}} i \tilde{n}_{k}}
\end{gathered}
$$

$\dot{S}_{i}, \dot{U}_{i}, \dot{H}_{k i}, \dot{F}_{k i}-$ DFT coefficients of the useful signal, impulse response of the channel, impulse response of the analysis and synthesis filters, respectively, $\hat{\dot{K}}_{k i}-$ the DFT coefficients of the impulse response of the filter-compensator fractional delay interpolated $M / M_{0}$ times $M / M_{0}, \dot{K}_{c \phi i}$ - DFT coefficients of the impulse response of a filter matched to a useful signal $\dot{s}(n)$, $n=0 \div N-1, \quad b=\frac{N_{D F T}}{M}-$ proportionality coefficient. The number of DFT points $N_{D F T}$ was chosen for reasons that a cyclic shift of the spectrum by $\frac{2 \pi}{M}$ at normalized frequencies is equivalent to a cyclic shift of the DFT coefficients in the frequency domain by $b$.

Also, this section presents the results of an experiment to compensate for dispersion distortion in a wideband signal on a single-hope HF radiolink with a length of $\sim 2900 \mathrm{~km}$. The experiment used a wideband signal with direct spreading of the spectrum with a pseudo-random sequence consisting of 512 symbol and with a rectangular envelope function, the width of the main lobe of the signal spectrum was $400 \mathrm{kHz}$. 
Among the experimental recordings of the signals were selected those where there is a minimum amount of station interference.

The operating frequencies were chosen near the MUF, 0.851.05 of the predicted one, since on them, the dispersion distortion is significant. Compensation was carried out by the methods proposed in the article, based on banks of analysis-synthesis filters. The dispersion characteristic slope was tentatively estimated by the maximum likelihood method.

In the course of the experiment, five different records were processed, the MF responses were constructed for the signal not processed by the bank, for the signal not processed by the filtercompensator and the compensation signal embedded in the computationally efficient filter bank scheme and also determined the gain in compensation (Figure 8).

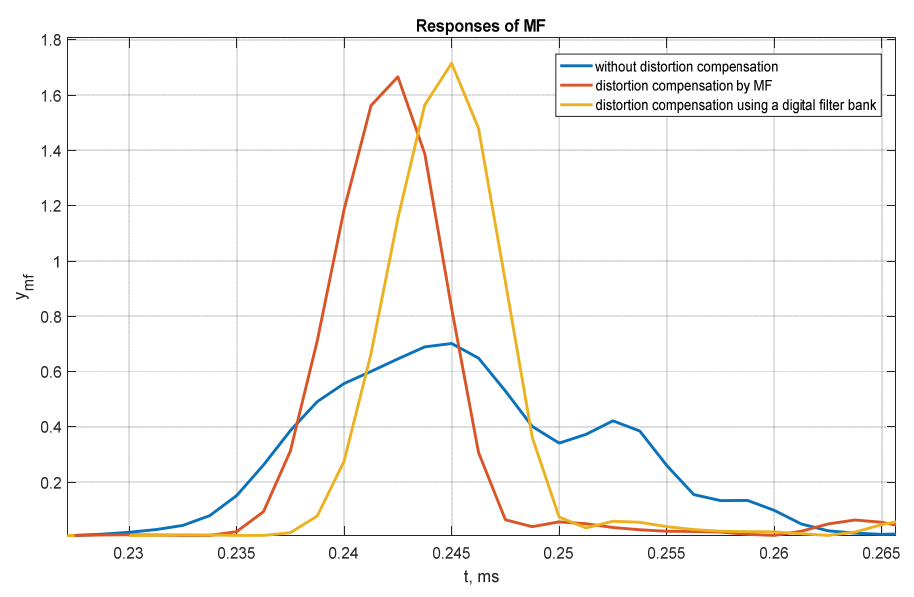

Figure 8. Experimentally obtained MF responses at $s=140 \mu \mathrm{s} / \mathrm{MHz}$ (Record 1)

Compensation ain is etermined by $K_{M F}=20 \lg \left[\frac{\max \left(\left|\dot{q}_{M F}\left(n_{*}\right)\right|\right)}{\max \left(\left|\dot{q}\left(n_{*}\right)\right|\right)}\right]$ for the filter-compensator and $K_{\text {comp.bank }}=20 \lg \left[\frac{\max \left(\left|\dot{q}_{\text {comp.bank }}\left(n_{*}\right)\right|\right)}{\max \left(\left|\dot{q}\left(n_{*}\right)\right|\right)}\right]$ for computationally efficient filter bank scheme, respectively, $\dot{q}\left(n_{*}\right)$ - the response of MF without compensation, $\dot{q}_{M F}\left(n_{*}\right)$ - the response of MF with compensation by the filter-compensator, $\dot{q}_{\text {comp.bank }}\left(n_{*}\right)-$ the response of MF with compensation by the filter bank. The results of the experiment are summarized in Table 3.

The theoretical values of the gain in terms of SNR for different values are summarized in Table 4 . The theoretical gain in compensation was determined as the difference between the SNR without compensation and with compensation. The theoretical value of the SNR is calculated by the formula (9).
The results of experimental compensation for dispersion distortions

\begin{tabular}{|c|c|c|c|}
\hline Record \# & $s, \mu \mathrm{s} / \mathrm{MHz}$ & $K_{M F}, \mathrm{~dB}$ & $K_{\text {comp.bank }}, \mathrm{dB}$ \\
\hline 1 & 14 & 3.8 & 3.9 \\
\hline 2 & 8 & 2.7 & 2.9 \\
\hline 3 & 8 & 2.2 & 2.4 \\
\hline 4 & 8 & 3.3 & 3.2 \\
\hline 5 & 13 & 1.4 & 1.6 \\
\hline
\end{tabular}

Table 4

The gain in theoretical compensation for dispersion distortion for a signal with a rectangular envelope function

\begin{tabular}{|c|c|c|}
\hline$s, \mu \mathrm{s} / \mathrm{MHz}$ & $K_{\text {comp.bank }}, \mathrm{dB}$ & $K_{M F}, \mathrm{~dB}$ \\
\hline 80 & 4. & 4.37 \\
\hline 130 & 6 & 6.38 \\
\hline 140 & 6 & 6.67 \\
\hline
\end{tabular}

\section{Conclusion}

The article proposes the dispersion distortion compensator based on a bank of digital filters with a computationally efficient implementation. By calculation and using simulation, the operability of the proposed device was demonstrated. The expression was obtained for determining the signal-to-noise ratio at the output of the MF and the filter bank with compensation. In this article, we estimated the required number of channels in a dispersion compensation device based on a bank of digital filters. New expressions were obtained that allow, for a given level of the mean square or maximum deviation of the phase response of the channel + filter bank with compensation system, to determine the minimum required number of filters $2 M$. Comparison of compensation algorithms was carried out on the basis of a filter bank and a filter-compensator, according to the results of which it was concluded that the compensator in the filter bank for the given values of $\varphi_{r m s}$ requires computational operations less than 1.5 times than the filter-compensator, and for the given values of $\varphi_{\text {min max }}$, it is less than about 2 times. In addition, the article presents the results of field tests to compensate for dispersion distortions in a broadband signal and their comparison with theoretical data. The maximum gain in experimental compensation is $3.9 \mathrm{~dB}$, and the minimum is $1.6 \mathrm{~dB}$ for various records. The theoretical gain is $4.36 \mathrm{~dB}$ for $s=80 \mu \mathrm{s} / \mathrm{MHz}, 6.37 \mathrm{~dB}$ for $s=130$ $\mu \mathrm{s} / \mathrm{MHz}$ and $6.66 \mathrm{~dB}$ for $s=140 \mu \mathrm{s} / \mathrm{MHz}$.

\section{References}

1. MIL-STD-188-110C Departament of Defence interface standart. Interoperability and performance standards for data modems. US Department of Defense. 3 January 2012.

2. M.B. Jorgenson, R.W. Johnson, R.W. Nelson (2013). An Extension of Wideband HF Capabilities. IEEE Military Communications Conference, pp. 1202-1206. 
3. MIL-STD-188-110D Departament of Defence interface standart. Interoperability and performance standards for data modems. US Department of Defense. 29 December 2017.

4. D.V. Ivanov. (2006). Methods and mathematical models for study of the propagation of decameter complex signals and correction its dispersion distortions. MarSTU, Yoshkar-Ola.

5. E.M. Lobov, I.S. Kosilov. (2011). Calculation of noise immunity of broadband ionospheric radio links using noise-like signals based on prediction data. T-Comm. Vol. 5. No. 11, pp. 68-70.

6. E.M. Lobov, E.O. Smerdova. (2017). Investigation of the quality of algorithms for estimating the slope of the ionospheric channel dispersion characteristics. Telecommunications. No. 6, pp. 28-31.

7. E.M. Lobov, E.O. Smerdova, N.A. Kandaurov, I.S. Kosilov, B.A. Elsukov. (2017). Optimum estimation and filtering of the ionospheric channel dispersion characteristics slope algorithms. 2017 Systems of signal synchronization, generating and processing in telecommunications (SINKHROINFO), DOI: 10.1109/SINKHROINFO.2017.7997537

8. E.M. Lobov, Lobova E.O., Kandaurov N.A. (2018). Optimum tracking dispersion distortion compensator. Telecommunications. No. 5, pp. 85-89.

9. S.S. Adjemov, E.M. Lobov, N.A. Kandaurov, E.O. Lobova. (2019). Methods and algorithms of broadband HF signals dispersion distortion compensation. 2019 Systems of Signal Synchronization, Generating and Processing in Telecommunications, SYNCHROINFO 2019, Yaroslavl, 1-3 July 2019, 9 p. DOI: 10.1109/SYNCHROINFO.2019.8814074

10. E.O. Lobova, N.A. Kandaurov. (2019). Experimental Results of Dispersion Distortion Compensation of Wideband Signals with a Device Based on a Digital Filter Bank. 2019 Systems of Signals Generating and Processing in the Field of on Board Communications, SOSG 2019, Moscow, 20-21 March 2019, 8 p. (DOI: 10.1109/SOSG.2019.8706758)
11. V. Vityazev. (2017). Multi-speed signal processing. Moscow: Hot line - Telecom. 336 p.

12. H.S. Malvar. (1992). Signal Processing with Lapped Transforms, Artech House, Norwood, MA. 336 p.

13. E.O. Lobova, E.M. Lobov, B.A. Elsukov. (2018). Broadband Signals Dispersion Distortions Compensator Based on the Digital Filters Bank. Reports of the 20th International Conference "Digital Signal Processing and its Application - DSPA-2018", Moscow, Russia, Vol. 2, pp. 487-491.

14. E.O. Lobova, E.M. Lobov, B.A. Elsukov (2018). Wideband signals dispersion distortion compensator based on digital filter banks. 2018 Systems of signals generating and processing in the field of on board communications, Moscow, 14-15 March 2018, 4 p. DOI: 10.1109/SOSG.2018.8350615

15. E.M. Lobov, E.O. Lobova, A.A. Kurochkin (2018). Computationally simplified realization of the compensator of dispersion distortions on the basis of the filter bank. 2018 Systems of Signal Synchronization, Generating and Processing in Telecommunications (SYNCHROINFO), Minsk, 4-5 July, 2018, 4 p. DOI: 10.1109/SYNCHROINFO.2018.8457058

16. T. Karp, N.J. Fliege. Modified DFT Filter Banks with Perfect Reconstruction. IEEE Transactions on Circuits and Systems - II: Ana$\log$ and Digital Signal Processing, vol. 46, 11, pp. 1404-1414, DOI: 10.1109/82.803480

17. V.S. Priputin, V.R. Magsumov, E.O. Lobova. (2019). Analysis of Digital Filter Prototype Design Methods for High-Speed Signal Processing Based on Polyphase Filter Bank. 2019 Systems of Signals Generating and Processing in the Field of on Board Communications, SOSG 2019, Moscow, 20-21 March 2019, 4 p. DOI: 10.1109/SOSG.2019.8706751

\title{
КОМПЕНСАТОР ДИСПЕРСИОННЫХ ИСКАЖЕНИЙ ШИРОКОПОЛОСНЫХ СИГНАЛОВ ДЕКАМЕТРОВОГО ДИАПАЗОНА, ПОСТРОЕННЫЙ НА БАЗЕ БАНКА ЦИФРОВЫХ ФИЛЬТРОВ. ТЕОРИЯ И ЭКСПЕРИМЕНТ
}

Чиров Денис Сергеевич, Московский технический университет связи и информатики, Москва, Poccuя, den-chirov@уаndex.ru Лобова Елизавета Олеговна, Московский технический университет связи и информатики, Москва, Poсcия, lizabeth2@mail.ru

\begin{abstract}
Аннотация
Предложена вычислительно эффективная схема устройства компенсации дисперсионных искажений, основанная на модификации классической схемы 2М-канального цифрового банка фильтров. Основанная идея компенсации дисперсионных искажений состоит в выравнивании временной задержки и устранении фазового сдвига сигнала, так как частотная дисперсия влияет на сигнал, внося дополнительную групповую задержку и фазовый сдвиг. Устройство компенсации дисперсионных искажений состоит из набора КИХ-фильтров интерполяторов и линии задержки. Набор КИХ-фильтров, устраняющих дробную задержку, реализован в схеме компенсации путем повторной оцифровки сигнала с помощью интерполяционного полинома Лагранжа 19-й степени. Каждый из КИХ-фильтров умножается на коэффициент, который устраняет определенный фазовый сдвиг. Линия задержки необходима для устранения целой части задержки. Также, предложен метод оценки необходимого количества каналов в устройстве компенсации дисперсионных искажений для достижения заданного качества компенсации, количественно определяемого среднеквадратичным и максимальным отклонением ФЧХ системы канал+компенсатор. Предложенный алгоритм компенсации сравнивается с алгоритмом компенсации на основе классического фильтра-компенсатора по качеству и сложности реализации. Получены аналитические выражения для приближенного расчета максимального и среднеквадратичного отклонения ФЧХ системы канал+компенсатор, отражающие зависимость отклонения ФЧХ от числа частотных подканалов, порядка интерполяционного полинома интерполятора, длины полифазных компонент фильтра прототипа, наклона дисперсионной характеристики и полосы пропускания банка фильтров. Представлено теоретическое и экспериментальное исследование, цель которого состоит в том, чтобы подтвердить работоспособность и эффективность (с точки зрения отношения сигнал/шум) алгоритма компенсации дисперсионных искажений широкополосных сигналов в декаметровом диапазоне, встроенного в банк фильтров цифрового анализа-синтеза.
\end{abstract}


Ключевые слова: декаметровая радиосвязь, широкополосные сигналы, дисперсионные искажения, банк цифровых фильтров, ионосфера.

\section{Литература}

I. MIL-STD-I88-I IOC. Departament of Defence interface standart. Interoperability and performance standards for data modems. US Department of Defense. 3 January 2012.

2. Jorgenson M.B., Johnson R.W., Nelson R.W. An Extension of Wideband HF Capabilities // IEEE Military Communications Conference. 2013. Pp. 1202-1206.

3. MIL-STD-I88-IIOD. Departament of Defence interface standart. Interoperability and performance standards for data modems. US Department of Defense. 29 December 2017.

4. Иванов Д.В. Методы и математические модели исследования распространения в ионосфере сложных декаметровых сигналов и коррекции их дисперсионных искажений: монография. Йошкар-Ола: Марийский гос. технический ун-т, 2006. 266 с.

5. Лобов Е.М., Косилов И.С. Расчет помехоустойчивости широкополосных ионосферных с применением шумоподобных сигналов на основе данных прогнозирования // Т-сотm: Телекоммуникации и транспорт, 20II, Т. 5, № II. С. 68-70.

6. Лобов Е.М., Смердова Е.О. Исследование качества алгоритмов оценки наклона дисперсионной характеристики ионосферного канала // Электросвязь, 20I7, №6. С. 28-3І.

7. Lobov E.M., Smerdova E.O., Kandaurov N.A., Kosilov I.S., Elsukov B.A. Optimum estimation and filtering of the ionospheric channel dispersion characteristics slope algorithms // Systems of signal synchronization, generating and processing in telecommunications (SINKHROINFO), 2017 (DOI: I0.I I09/SINKHROINFO.2017.7997537)

8. Лобов Е.М., Лобова Е.О., Кандауров Н.А. Оптимальный следящий компенсатор дисперсионных искажений широкополосных сигналов // Электросвязь, 2018, №5. С. 85-89.

9. Adjemov S.S., Lobov E.M., Kandaurov N.A., Lobova E.O. Methods and algorithms of broadband HF signals dispersion distortion compensation // 2019 Systems of Signal Synchronization, Generating and Processing in Telecommunications, SYNCHROINFO 20I9, Yaroslavl, I-3 July 2019, 9p. (DOI: I0.II09/SYNCHROINFO.2019.88I4074)

10. Lobova E.O., Kandaurov N.A. Experimental Results of Dispersion Distortion Compensation of Wideband Signals with a Device Based on a Digital Filter Bank // 2019 Systems of Signals Generating and Processing in the Field of on Board Communications, SOSG 2019, Moscow, 20-2I March 2019, 8 p. (DOI: 10.1 I09/SOSG.2019.8706758)

II. Витязев В.В. Многоскоростная обработка сигналов. М.: Горячая линия-Телеком. 2017. 336 с.

12. Malvar H.S. Signal Processing with Lapped Transforms, Artech House, Norwood, MA, 1992, 336 p.

І3. Лобова Е.О., Лобов Е.М., Елсуков Б.А. Устройство компенсации дисперсионных искажений на базе банка цифровых фильтров // DSPA: Вопросы применения цифровой обработки сигналов, 20I8, Т.3, №3. С. 60-65.

I4. Lobova E.O., Lobov E.M., Elsukov B.A. Wideband signals dispersion distortion compensator based on digital filter banks // 2018 Systems of signals generating and processing in the field of on board communications, Moscow, I4-15 March 20I8, 4 p. DOI: 10.1 I09/SOSG.2018.83506I5

15. Lobov E.M., Lobova E.O., Kurochkin A.A. Computationally simplified realization of the compensator of dispersion distortions on the basis of the filter bank // 2018 Systems of Signal Synchronization, Generating and Processing in Telecommunications (SYNCHROINFO), Minsk, 4-5 July, 20I8, 4 p. (DOI: I0.I I09/SYNCHROINFO.20I8.8457058)

16. Karp T., Fliege N.J. Modified DFT Filter Banks with Perfect Reconstruction // IEEE Transactions on Circuits and Systems - II: Analog and Digital Signal Processing, vol. 46, II, PP. I404-I4 I4, DOI: I0.I 109/82.803480

17. Priputin V.S., Magsumov V.R., Lobova E.O. Analysis of Digital Filter Prototype Design Methods for High-Speed Signal Processing Based on Polyphase Filter Bank // 2019 Systems of Signals Generating and Processing in the Field of on Board Communications, SOSG 2019, Moscow, 20-2I March 2019, 4p. (DOI: I0.1 I09/SOSG.2019.870675I)

\section{Информация об авторах:}

Чиров Денис Сергеевич, г.н.с., д.т.н., доцент, Московский технический университет связи и информатики, Москва, Россия

Лобова Елизавета Олеговна, аспирант, м.н.с., Московский технический университет связи и информатики, Москва, Россия 